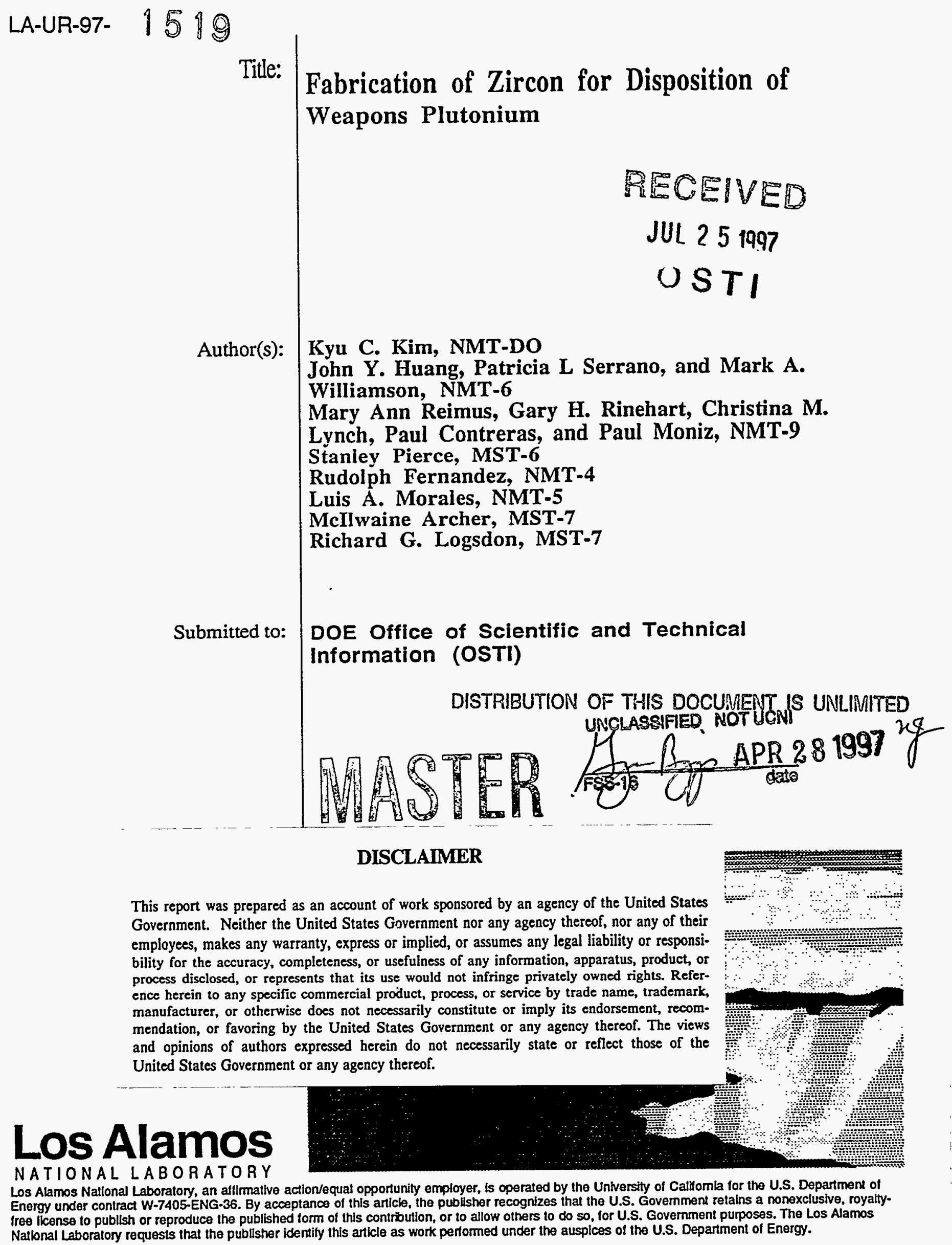




\section{DISCLAIMIER}

Portions of this document may be illegible in electronic image products. Images are produced from the best available original document. 


\title{
Fabrication of Zircon for Disposition of Weapons Plutonium
}

\author{
Kyu C. Kim*, John Y. Huang*, Patricia L Serrano, Mary Ann Reimus, \\ Gary H. Rinehart, Christina M. Lynch,Paul Contreras, Paul Moniz, \\ Stanley Pierce, Rudolph Fernandez, Mcllwaine Archer, Richard G. Logsdon, \\ Luis A. Morales, and Mark A. Williamson
}

\begin{abstract}
This is the final report of a one-year, Laboratory-Directed Research and Development (LDRD) project at the Los Alamos National Laboratory (LANL). In an effort to address the problems of long term storage and nuclear waste minimization, zircon has been proposed as a host medium for plutonium and other actinides recovered from dismantled nuclear weapons. The objective of this work is to investigate the feasibility of large scale fabrication of Pu-bearing zircon. Since $\mathrm{PuO}_{2}$ is thermodynamically less stable than $\mathrm{ZrO}_{2}$, it is expected that the process parameters determined for synthesizing $\mathrm{ZrSiO}_{4}$ (zircon) would be applicable to those for $\mathrm{PuSiO}_{4}$ (Pu-zircon). Furthermore, since the foremost concem in plutonium processing is the potential for contamination release, this work emphasizes the development of process parameters, using zircon first, to anticipate potential material problems in the containment system for reaction mixtures during processing. Stoichiometric mixtures of $\mathrm{ZrO}_{2}$ and $\mathrm{SiO}_{2}$, in hundred-gram batches, have been subjected to hot isostatic pressing (HIP) at temperatures near $1500^{\circ} \mathrm{C}$ and pressures approximately $10,000 \mathrm{psi}$. The product materials have been analyzed by $\mathrm{x}$-ray powder diffraction, and are found to consist of zircon after approximately two hours of reaction time. From this work, it is clear that the fabrication of large quantities of $\mathrm{Pu}$-zircon is feasible. The most notable result of this work is evidence for the existence of container problems. This result, in turn, suggests potential solutions to these problems. Experiments with the quartz inner container, the glass sealant, a sacrificial metal barrier, and a metal outer container are being investigated to mitigate these potential hazards.
\end{abstract}

\section{Background and Research Objectives}

Zircon, due to its well-known long-term durability ( $\sim 10^{9}$ years) in the geologic environment, has been proposed [1] as a host medium for storage of $\mathrm{Pu}$ and other actinides recovered from dismantled nuclear weapons. Much is known about the structure (I41/amd; $\mathrm{Z}=4$ ) of this single-phase mineral and its homologs (e.g. Hf, Th, $\mathrm{Pa}, \mathrm{U}, \mathrm{Np}, \mathrm{Pu}$ ). It is clear that zircon-type orthosilicate structures can accommodate metal cations having radii both smaller and larger than that of the $\mathrm{Zr}$ ion in zircon. Natural zircon has been found to contain approximately

*Principal investigators, email: kck@lanl.gov and jhuang@lanl.gov 
$5000 \mathrm{ppm}$ of $\mathrm{U}$ and $\mathrm{Th}$. Some of the cations found in natural zircon (e.g., Gd, Hf) are strong absorbers for thermal neutrons. Laboratory scale samples of zircon doped with up to $10 \mathrm{wt}$.\% of Pu have been prepared [2] for conducting accelerated tests on the effect of radiation damage on the structure and property changes and the phase stability in simulated geological conditions.

Furthermore, small samples of pure $\mathrm{PuSiO}_{4}$ have been prepared [3], which suggests that it is possible to substitute $\mathrm{Zr}$ with more than $10 \mathrm{wt} \%$ of $\mathrm{Pu}$. From the point of view of nuclear waste minimization, it is desirable that the upper limit of Pu solubility in zircon be determined. While exploring the potential for increasing the Pu loading in zircon, the issues of criticality safety need to be investigated so that the optimum waste form can be determined.

Various methods for synthesizing laboratory quantities of zircon have been investigated $[4,5]$. However, simultaneous application of high-temperature and high-pressure to enhance the solid state reaction has not been attempted, especially for zircon doped with large quantities of $\mathrm{Pu}$. With the existing equipment, such as the hot press and hot isostatic press in the Plutonium Facility, LANL is in a good position to develop the technology for large-scale fabrication of Pu-bearing zircon and, therefore, provide the nation with an alternative solution to the nuclear material disposition problem.

Our aim was to obtain the following information, which is essential to large-scale fabrication of Pu-bearing zircon: 1) the process parameters for large-scale fabrication of zircon with desirable Pu-loading and 2) the solubility limit of $\mathrm{Pu}$ in zircon. This information is important from the standpoint of waste volume minimization.

\section{Importance to LANL's Science and Technology Base and National R\&D Needs}

Although several methods for synthesizing small quantities of Pu-bearing zircon have been investigated, large scale fabrication based on the simultaneous application of high-temperature and high-pressure processing conditions has not been attempted. The success of this work will allow us to address the technical problems related to short-term and long-term storage of weapons nuclear materials. The result of this effort will enhance the Laboratory's capability for solving plutonium disposition problems. 


\section{Scientific Approach and Accomplishments}

\section{Approach}

Since the main objective of this work is to investigate the feasibility of large scale fabrication of Pu-bearing zircon, it is of utmost importance to be able to achieve this goal without contamination release to the work environment. Therefore, the approach taken in this work is to use the synthesis of zircon to explore potential problems in the containment of materiais during processing. Furthermore, since $\mathrm{PuO}_{2}$ is thermodynamically less stable than $\mathrm{ZrO}_{2}$, the processing parameters developed for the synthesis of zircon would be applicable to those for Pu-zircon.

The process to be used is hot isostatic pressing (HIP). The equipment provides high temperature in the reaction chamber through resistively heated graphite heating elements. It provides high pressure by compressing inert argon gas supplied from gas cylinders to the reaction chamber. The material to be "hipped" is contained inside compressible containers, typically fabricated from thin metals, and is compressed with equal force from all directions.

For "hipping" zircon, a container made of high meiting refractory metal is desirable. However, most metals are thermodynamically unstable, (and the more so the higher the temperature), with respect to the formation of their oxides. Since the starting materials for zircon are oxides, the oxidation of the container materials is inevitable, unless some sort of barrier (inner container) is provided to separate the reaction mixture from the metal container. But this inner container must also be compressible as well as chemically inert to the reaction mixture.

In anticipation of fabricating Pu-zircon at the Plutonium Facility, some schemes need to be developed for packaging the reaction-mixture/container assembly. First, the powder mixture has to be loaded into the inner container inside a glovebox. Then, for safety reasons, the container has to be assembled and sealed without the use of excessive heat, for example, from a hydrogen/oxygen flame. Thereafter, this inner container will be transferred from a glovebox into the "cold" outer metal container in an introductory hood with the outer container maintained free of contamination. The metal container will then be welded in a separate "cold" TIG welding hood. Finally, the outer container has to maintain its integrity after the processing, otherwise the process equipment contained inside a hood will be contaminated.

Based on these criteria, tantalum is chosen for the outer container, and quartz the inner one. Tantalum is chosen based on its high melting point of $3017^{\circ} \mathrm{C}$, its availability, and its relative ease of welding. The choice of quartz is based on the known phase behavior of the $\mathrm{ZrO}_{2} / \mathrm{SiO}_{2}$ system. The phase diagram of this system indicates that zircon does not form any compounds with $\mathrm{SiO}_{2}$ in the temperature range of interest. Furthermore, quartz softens at temperatures above $1200^{\circ} \mathrm{C}$, and, therefore, can be compressed. Nevertheless, the potential for reactions among $\mathrm{Ta}, \mathrm{ZrO}_{2}$ and $\mathrm{SiO}_{2}$ 
still exists. Based on this containment system, the range of temperature, pressure, and time will be explored to provide a reasonable processing scheme.

\section{Experimental}

Materials. The zirconium oxide was obtained from Teledyne Wah Chang Albany. This crystal grade material (Lot No. 275) has higher than $99 \%$ purity and was used as purchased. The silicon oxide is floated silica powder (Lot No. 942673A) purchased from Fisher Scientific, with unspecified purity. Both materials were subjected to particle size analysis using a stack of 2.25 inch ID disposable nylon sieves ranging from 100 mesh to 400 mesh.

To determine the amount of material that can be loaded into a container of given size, the tap density of each powder was measured. To homogenize the reactants, equimolar mixtures of $\mathrm{ZrO}_{2}$ and $\mathrm{SiO}_{2}$ were loaded into disposable plastic mill jars, which have built-in baffled walls. The mill jar was inserted into a chromed steel sleeve and the assembly was placed on the rollers of a Labmill-8000 (Cole-Parmer) mixer. The material was mixed at a rotational speed of $136 \mathrm{rpm}$ for two hours.

Containers. The quartz containers were fabricated from two (one male and one female) size 29/42 ground quartz joints, purchased from Quartz Scientific, Inc.. The female part has 26 mm inside diameter and is $8.5 \mathrm{~cm}$ long providing an internal volume of approximately $45 \mathrm{~cm}^{3}$. The tubing of the male part is cut and made into a lid for the container.

For the joining and sealing of quartz containers inside gloveboxes without excessive heat, it was discovered that a commercial glass paste, PK-1015, available from Vitta Corporation, can serve the purpose. This material is a pure borosilicate glass with a low thermal expansion coefficient. Applied in thin layers, it can join the quartz parts without any stress due to mismatch of thermal expansion. This paste eliminates the direct fusing of quartz parts, which necessitated very high temperatures of approximately $1800^{\circ} \mathrm{C}$. After the sealing is completed, a hermetic seal is obtained between the quartz parts. This material has been tested successfully at our glass shop and used routinely.

The tantalum containers were purchased from Reliance Metalcenter in the form of tubings and thin sheets. The former have 1.5 inches outside diameter and are 5 inches long. Both the tubings and the sheets are 0.020 inches thick. The sheets are cut to proper size and spin-formed into shallow cups in order to be press-fitted to the ends of tubings. The lids and the tubing are joined together using a tungsten inert gas welder. The welding process is developed in the "cold" area and the parameters determined are transferred to the equipment inside the "hot" area.

Hipping. After the quartz containers have been cleaned with ethanol in an ultrasonic cleaner and dried, the powder mixture is weighed into the containers. Approximately $80 \mathrm{~g}$ is loaded in each experiment. The PK-1015 glass paste is then applied to the joints on the quartz 
containers. The joints are hand twisted against each other to provide a good and uniform seal. The joints are not heat treated after applying the sealant. The sealed quartz container is then placed into a tantalum container that is already welded on the bottom end.

The top end of the container is welded inside a He-inerted glovebox using a TIG welder. A procedure has to be developed to avoid blow-out caused by the hot entrapped gas inside the container momentarily before encapsulation is completed. This procedure includes a normal welding program, developed after several trial iterations, for the major fraction of welds, pausing for the welds to cool and to release the gas pressure, and then quickly completing the enclosure.

The reaction mixture inside the double containment system is placed into an ABB model QIH-3 hot isostatic press. The package is placed in a tantalum cup before being introduced into the graphite furnace region. The furnace is capable of attaining temperatures up to $2000^{\circ} \mathrm{C}$ and pressures up to 30,000 psi.

A typical hipping experiment involves 6 program segments, as shown in Figure 1:

Segment \#1. Increase the pressure to $50 \mathrm{psi}$ in one minute while the furnace is at ambient temperature.

Segment \#2. Increase temperature at a rate of $25^{\circ} \mathrm{C} / \mathrm{min}$ to $1000^{\circ} \mathrm{C}$ while holding pressure at ambient, to cure the quartz seal.

Segment \#3. Increase pressure to the desired value, e.g., 4,000 psi, in 25 minutes and simultaneously increase temperature to the desired value, e.g., $1450^{\circ} \mathrm{C}$.

Segment \#4. Maintain temperature and pressure at desired values for preselected duration, e.g., 120 minutes.

$\underline{\text { Segment \#5. }}$. Decrease temperature to below $1200^{\circ} \mathrm{C}$ (the softening temperature of quartz) in 15 minutes while holding pressure constant.

Segment \#6. Decrease temperature and pressure to ambient in 50 minutes.

A summary of the hipping experiments is shown below:

$\begin{array}{cccccc}\text { Run ID } & \begin{array}{c}\text { Maximum } \\ \text { Temperature }\end{array} & \begin{array}{c}\text { Maximum } \\ \text { Pressure }\end{array} & \begin{array}{c}\text { Holding } \\ \text { Time }\end{array} & \begin{array}{c}\text { No. of } \\ \text { Batches }\end{array} & \text { Product ID } \\ \text { hip-1 } & 1450^{\circ} \mathrm{C} & 4,000 \mathrm{psi} & 2 \mathrm{hrs} & 1 & \mathrm{Z} 004 \\ \text { hip-2 } & 1500^{\circ} \mathrm{C} & 10,000 \mathrm{psi} & 2 \mathrm{hrs} & 2 & \mathrm{Z} 006, \mathrm{Z} 007 \\ \text { hip-3 } & 1500^{\circ} \mathrm{C} & 10,000 \mathrm{psi} & 6 \mathrm{hrs} & 1 & \mathrm{Z} 008 \\ \text { hip-3 } & 1500^{\circ} \mathrm{C} & 10,000 \mathrm{psi} & 8 \mathrm{hrs} & 1 & \mathrm{Z} 009\end{array}$

Material characterization. X-ray powder diffraction patterns were taken from each product as well as from the starting mixture. A Debye-Scherrer camera with $114.6 \mathrm{~mm}$ diameter was used. The sample was placed in a $0.2 \mathrm{~mm}$ diameter capillary tube. Due to the presence of 
high background intensity, it was found necessary to place 2 layers of aluminum foil on the film to reduce the background level. CuKa radiation was used at $35 \mathrm{keV}$ and $25 \mathrm{~mA}$ for 8 hours of exposure.

\section{Results}

Materials. The distribution of particle sizes is shown below:

$\begin{array}{cccc}\text { Mesh No. } & \text { Particle size, } \mu \mathrm{m} & \mathrm{ZrO}_{2}, \mathbf{w t} \% & \mathrm{SiO}_{2}, \mathbf{w t} \% \\ +100 & >149 & 0 & 20 \\ +200 & >74 & 0 & 55 \\ +325 & >44 & 60 & 25 \\ +400 & >37 & 25 & 0 \\ -400 & <37 & 15 & 0\end{array}$

The measured tap density of $\mathrm{ZrO}_{2}$ is $2.26 \mathrm{~g} / \mathrm{cm}^{3}$ and that of $\mathrm{SiO}_{2}, 1.17 \mathrm{~g} / \mathrm{cm}^{3}$. This gives a specific volume of $0.577 \mathrm{~cm}^{3} / \mathrm{g}$ for a mixture consisting of an equimolar ratio of $\mathrm{ZrO}_{2}$ and $\mathrm{SiO}_{2}$. Thus, a container with an internal volume of $45 \mathrm{~cm}^{3}$ can be packed with $78 \mathrm{~g}$ of this mixture.

Containment. The Ta container was compressed as expected. The welds were intact in all cases. In run hip-1, the top lid had a pin hole where it was pressed against the sharp edge on the quartz lid; the main body preserved its integrity; the inside wall showed discoloration. The metal became brittle and was relatively easy to break apart. In run hip-3, the quartz lid was modified to have smooth a surface, which prevented breaking of the metal. In two of the runs, which were subjected to maximum pressure of $10,000 \mathrm{psi}$, the metal containers became brittle and broke. It was clear that reactions between the tantalum and the quartz containers had taken place.

The joint in the quartz container held together in one piece. The major part of the container body broke into pieces and separated from the product material. In run hip-1, part of the body stuck to the product and was very difficult to separate; discoloration of quartz was evident. In other runs with higher temperature and pressure, the separation of "quartz" from products was easy.

Product Material. The product was monolithic. In run hip-1, it showed a glassy surface. Several areas had glass bulk material stuck on the surface and could not be removed easily. The interior of the body appeared to be homogeneous. The material was very difficult to break. A masonry chisel and a hammer were used to break it into chunks. A drill bit with a tungsten carbide tip was used to take samples from the interior. In run hip-2, the product showed slight yellow color and did not have the glassy surface. Some of the product from run hip-2 was pulverized into powder and hipped (in run hip-3) for 6 more hours. The end product showed gray color. 
Material Characterization. The results from $x$-ray powder diffraction are summarized in Tables 1 \& 2. Table 1 shows that 30 lines were observed in the starting material, and that almost all lines can be assigned to either monoclinic- $\mathrm{ZrO}_{2}$ or $\mathrm{SiO}_{2}$ (quartz). Table 2 shows that 39 lines were observed in the product from run hip-1. Out of the 39 lines, 25 are assignable to zircon, 11 are due to monoclinic- $\mathrm{ZrO}_{2}$, and only 3 are due to $\mathrm{SiO}_{2}$ (cristobalite). However, the 3 strongest lines are due to $\mathrm{ZrO}_{2}$ and $\mathrm{SiO}_{2}$. This indicates that zircon begins to form in approximately 2 hours of reaction time, but the reaction is nowhere near completion. The other samples from all products showed almost identical patterns and relative intensities. This indicates that the extent of reaction did not differ significantly for reaction times ranging from 2 to 8 hours. A more quantitative analysis using $\mathrm{x}$-ray diffractometer with samples that are mixed with standard reference material is necessary. Further product material characterization by chemical, analytical and metallographic techniques are underway.

\section{Conclusions}

1) Under the high-temperature and high-pressure conditions employed in this work, hundred-gram batches of $\mathrm{ZrO}_{2} / \mathrm{SiO}_{2}$ mixture began to react and form zircon in approximately 2 hours, although the reaction is far from complete. Considering the thermodynamic stability of $\mathrm{PuO}_{2}$ relative to $\mathrm{ZrO}_{2}$, i.e., $\mathrm{PuO}_{2}$ has less negative standard Gibb's free energy of formation than $\mathrm{ZrO}_{2}$, it is expected that the tendency for the formation of Pu-bearing zircon is higher. The result of this preliminary work indicates that it is feasible to fabricate large quantity of Pu-zircon. However, further developmental work is necessary.

2) This work revealed potential container problems that could be encountered at the developmental stage and suggested practicable solutions. The quartz inner container, the glass sealant, and the tantalum outer container all showed expected behavior. The containment system allowed the reaction mixture to be compressed isostatically. The separation of final products from the container materials was not difficuit. The reactions between tantalum, $\mathrm{SiO}_{2}$, and $\mathrm{ZrO}_{2}$ could be prevented by providing a sacrificial barrier between the inner and the outer containers. Clearly, further developmental work is needed to establish a safe process for large scale fabrication of $\mathrm{Pu}$ bearing zircon.

3) The process developed for joining quartz parts with the use of a special glass sealant, as an alternative to high-temperature fusion inside gloveboxes, is an innovative approach that is applicable to other operations in the Plutonium Facility. 


\section{References}

(1) Ewing, R., Lutze, W. and Weber, W., "Zircon: A host-phase for the disposal of weapons plutonium", J. Mater. Res.,10, 243, 1995.

(2) Weber, J., "Radiation-induced defects and amorphization in zircon", J. Mater. Res., $\mathbf{5}$, 2687 (1990).

(3) Keller, C., "Untersuchungen über die Germanate und Silikate des Typs $\mathrm{ABO}_{4}$ der vierwertigen Elemente Thorium bis Americium", Nukleonik, $\underline{\mathbf{5}}, 41$ (1963).

(4) Komarneni, S.and Roy, R, "Synthesis of Zircon", Zircon, Science and Technology, edited by Somiya, S., (Uchidarokakuho, Japan), pp 289-298, 1988.

(5) Mori, T., et. al., "Formation mechanism of $\mathrm{ZrSiO}_{4}$ powders", J. Mater. Sci.., 28 , 4970 (1993). 
Table 1. X-ray powder diffraction lines of starting material.

\begin{tabular}{|c|c|c|c|c|}
\hline Line No. & d-spacing / $\AA$ & Intensity & & lases (hkl) \\
\hline 1 & 4.236 & 10 & & $\mathrm{SiO}_{2}(100)$ \\
\hline 2 & 3.974 & 5 & $?$ & \\
\hline 3 & 3.660 & 10 & $\mathrm{ZrO2}(011.110)$ & \\
\hline 4 & 3.336 & 100 & & SiO2 (101) \\
\hline 5 & 3.157 & 90 & $2 \mathrm{nO} 2(-111)$ & \\
\hline 6 & 2.825 & 90 & $2 \mathrm{rO2}(111)$ & \\
\hline 7 & 2.609 & 10 & $\mathrm{ZrO} 2(020)$ & \\
\hline 8 & 2.531 & 5 & $\mathrm{ZrO2}(002)$ & \\
\hline 9 & 2.441 & 2 & & SiO2 (110) \\
\hline 10 & 2.272 & 2 & & $\mathrm{SiO} 2(102)$ \\
\hline 11 & 2.203 & 5 & $2-02(112)$ & SiO2 (111) \\
\hline 12 & 2.016 & 2 & & SiO2 (200) \\
\hline 13 & 1.980 & 5 & . & SiO2 (201) \\
\hline 14 & 1.846 & 10 & $\mathrm{ZrO} 2(220)$ & \\
\hline 15 & 1.815 & 40 & $\mathrm{ZrO} 2(022)$ & ISiO2 (112) \\
\hline 16 & 1.695 & 10 & $\mathrm{ZrO2}(003)$ & \\
\hline 17 & 1.651 & 20 & $2502(-311)$ & \\
\hline 18 & 1.606 & 10 & $2502(-113)$ & \\
\hline 19 & 1.581 & 10 & $\mathrm{ZrO} 2(-222)$ & \\
\hline 20 & 1.540 & 40 & $\mathrm{ZrO2}(203)$ & $\mathrm{SiO} 2(211)$ \\
\hline 21 & 1.503 & 2 & & \\
\hline 22 & 1.475 & 5 & $\mathrm{ZrO2}(113)$ & \\
\hline 23 & 1.446 & 2 & $\mathrm{ZrO2}(230)$ & - \\
\hline 24 & 1.418 & 10 & $2 \mathrm{rO} 2(-132)$ & \\
\hline 25 & 1.373 & 20 & & SiO2 $(203,301)$ \\
\hline 26 & 1.322 & 5 & $2502(-401)$ & \\
\hline 27 & 1.284 & 5 & & SiO2 (104) \\
\hline 28 & 1.253 & 5 & & $\mathrm{SiO} 2(302)$ \\
\hline 29 & 1.198 & 5 & & $\mathrm{SiO} 2(213.221)$ \\
\hline 30 & 1.181 & 5 & & SiO2 (114.310) \\
\hline PDF Number & & & $37-1484$ & $33-1161$ \\
\hline
\end{tabular}


Table 2. X-ray powder diffraction lines of product obtained from run \#hip-1.

\begin{tabular}{|c|c|c|c|c|c|}
\hline Line No. & d-spacing / \& & Intensity & & Phases (hkl) & \\
\hline 1 & 4.969 & 10 & & $\mathrm{ZrO2}(001)$ & \\
\hline 2 & 4.418 & 20 & Zircon (101) & & \\
\hline 3 & 4.040 & 50 & & & SiO2 (101) \\
\hline 4 & 3.685 & 30 & & $2502(110.011)$ & \\
\hline 5 & 3.314 & 25 & Zircon (200) & & \\
\hline 6 & 3.164 & 100 & & $2502(-111)$ & \\
\hline 7 & 2.840 & 90 & & $\mathrm{ZrO} 2(111)$ & $\mathrm{SiO} 2(102)$ \\
\hline 8 & 2.622 & 25 & Zircon (211) & & 1 \\
\hline 9 & 2.522 & 20 & Zircon (112) & & $\mathrm{SiO} 2(200)$ \\
\hline 10 & 2.335 & 15 & Zircon (220) & & \\
\hline 11 & 2.204 & 20 & Zircon (202) & & \\
\hline 12 & 2.069 & 5 & Zircon (301) & & \\
\hline 13 & 2.023 & 5 & & $2502(211)$ & \\
\hline 14 & 2.000 & 5 & & $2 \mathrm{rO} 2(-202)$ & \\
\hline 15 & 1.901 & 3 & Zircon (103) & & \\
\hline 16 & 1.855 & 10 & Zircon (222) & & \\
\hline 17 & 1.816 & 20 & & $\mathrm{ZrO} 2(022)$ & \\
\hline 18 & 1.705 & 10 & Zircon (312) & & \\
\hline 19 & 1.650 & 20 & Zircon $(123.400)$ & & \\
\hline 20 & 1.603 & 3 & & $\mathrm{ZrO} 2(-113,-131)$ & \\
\hline 21 & 1.538 & 20 & & |ZrO2 $(131,-203)$ & \\
\hline 22 & 1.498 & 3 & Zircon (004) & & \\
\hline 23 & 1.475 & 20 & Zircon $(303,420)$ & & \\
\hline 24 & 1.421 & 20 & Zircon (114) & & \\
\hline 25 & 1.363 & 5 & Zircon (024) & & \\
\hline 26 & 1.323 & 5 & Zircon (422) & 1 & \\
\hline 27 & 1.302 & 5 & & $\mathrm{ZrO} 02(040.312)$ & \\
\hline 28 & 1.263 & 5 & & $\mathrm{ZrO} 2(140)$ & \\
\hline 29 & 1.210 & 3 & Zircon (134) & & \\
\hline 30 & 1.185 & 3 & Zircon (512) & & \\
\hline 31 & 1.166 & 3 & Zircon (440) & & \\
\hline 32 & 1.103 & 3 & Zircon (433) & & \\
\hline 33 & 1.056 & 3 & Zircon (424) & & \\
\hline 34 & 1.032 & 3 & Zircon (602) & & \\
\hline 35 & 0.997 & 3 & Zircon (325) & & \\
\hline 36 & 0.899 & 3 & Zircon (552) & & \\
\hline 37 & 0.887 & 3 & Zircon (633) & & \\
\hline 38 & 0.805 & 5 & $?$ & & \\
\hline 39 & 0.790 & 3 & $?$ & & \\
\hline PDF Number & & & $06-0266$ & $37-1484$ & $39-1425$ \\
\hline
\end{tabular}




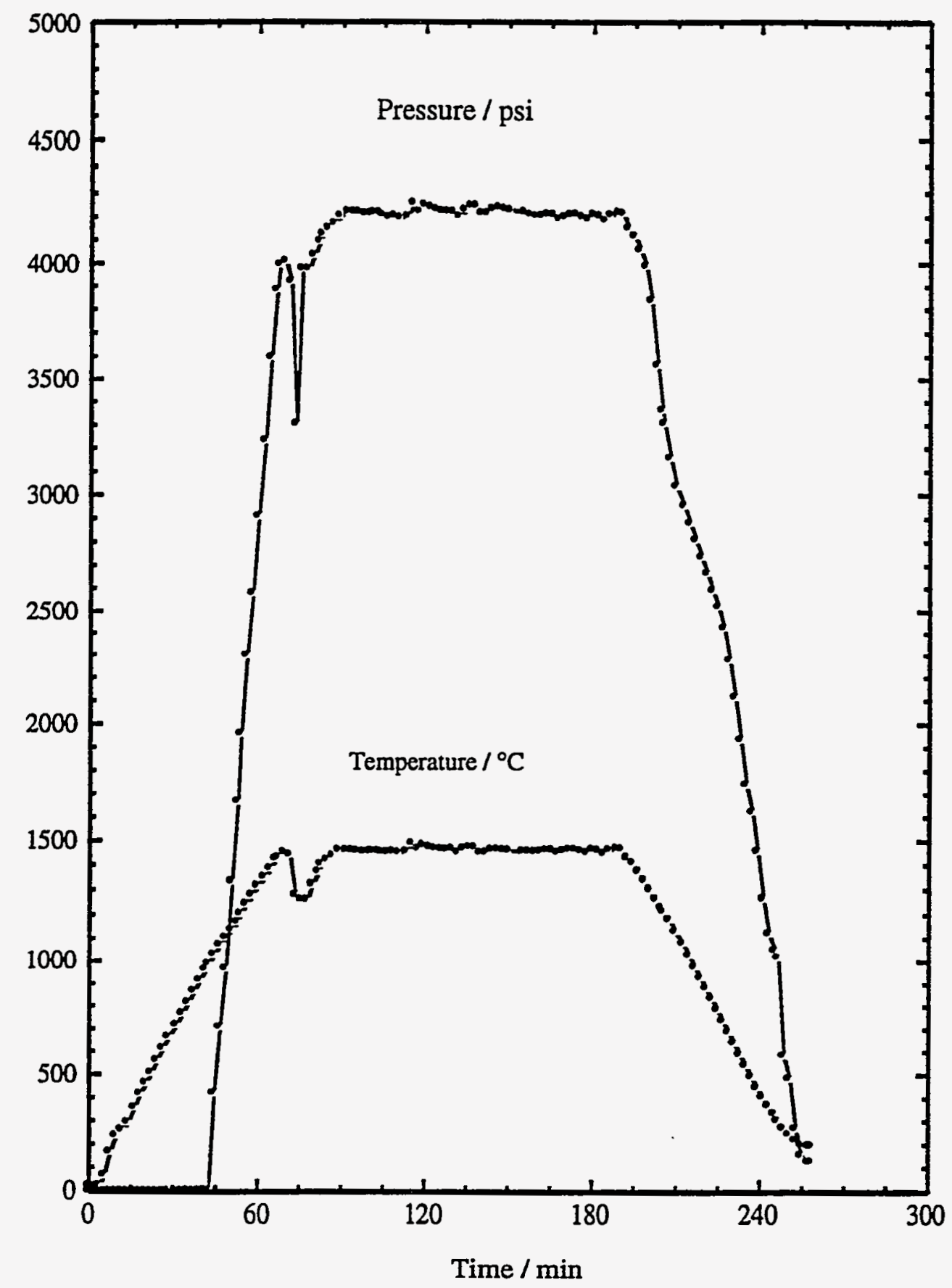

Figure 1. Temperature and pressure profiles for run hip-1. The other runs have similar profiles except that the holding times are longer. 

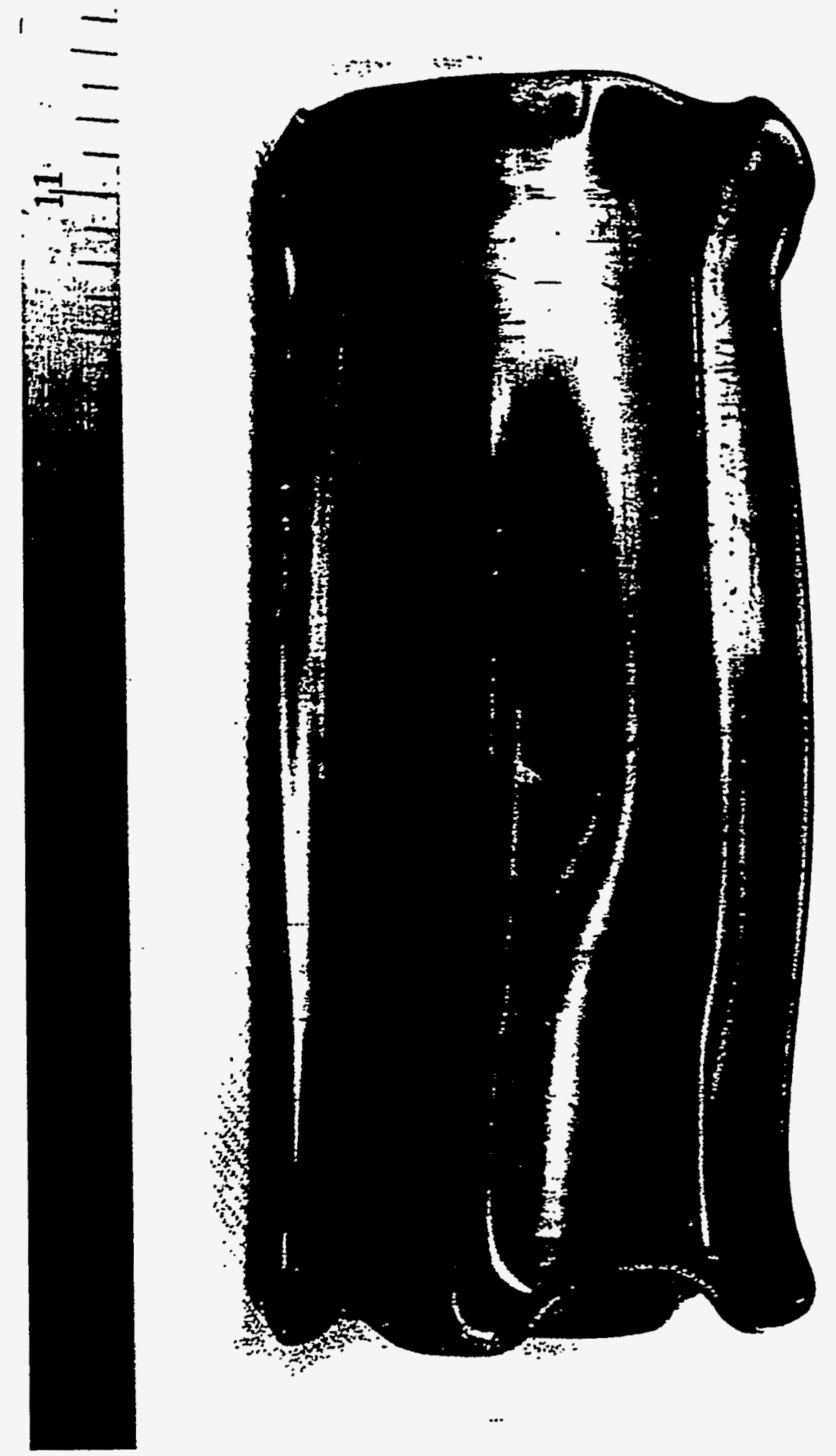

Figure 2. The tantalum container after run hip-1. This figure shows that the welds are intact and the body of the container remains in good condition after 2 hours at $1450^{\circ} \mathrm{C}$ and $4000 \mathrm{psi}$. 


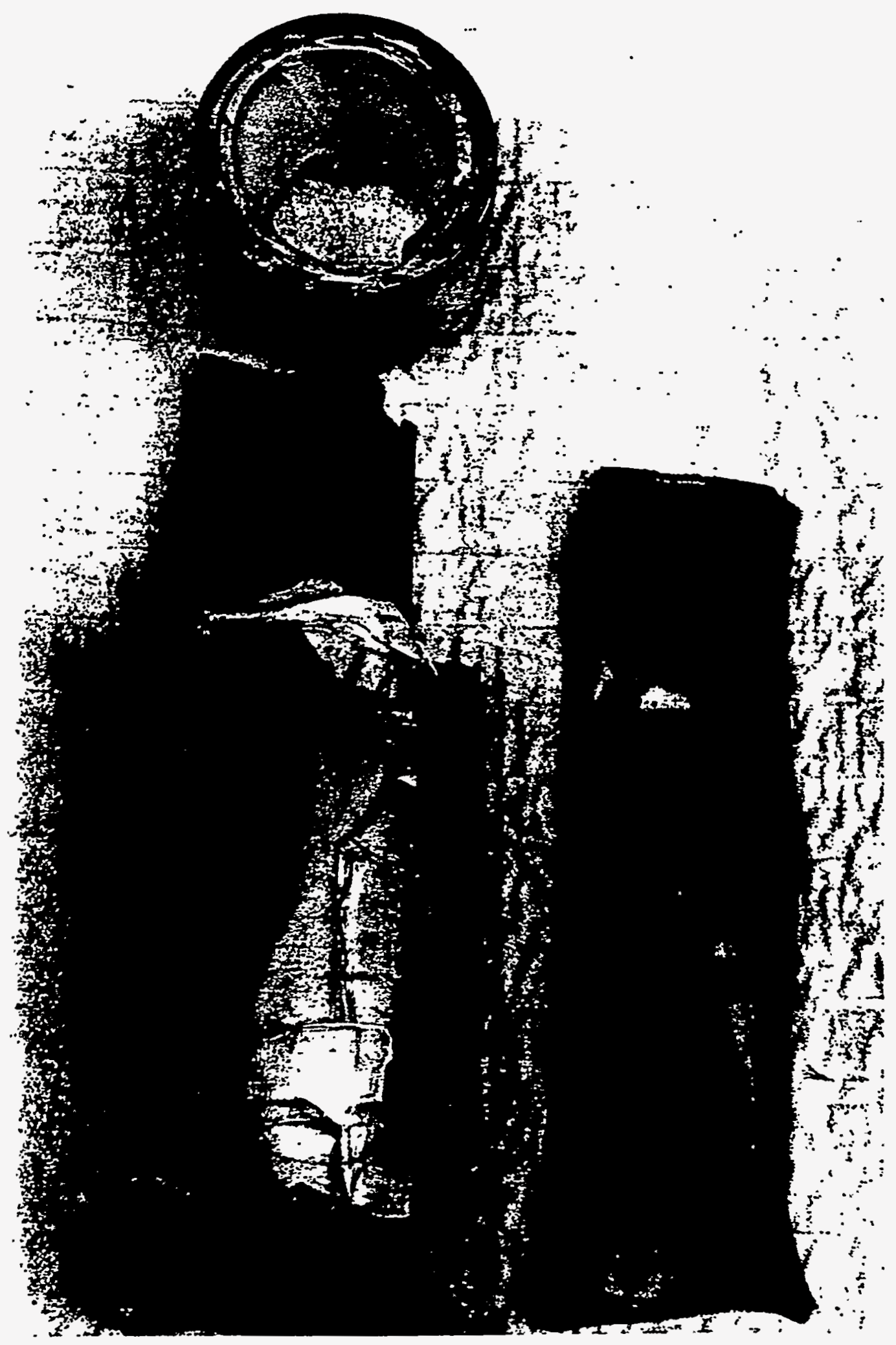

Figure 3. Materials inside of tantalum container after processing. The figure shows that the quartz joint holds together. The quartz container has broken into pieces and can be separated from product. 


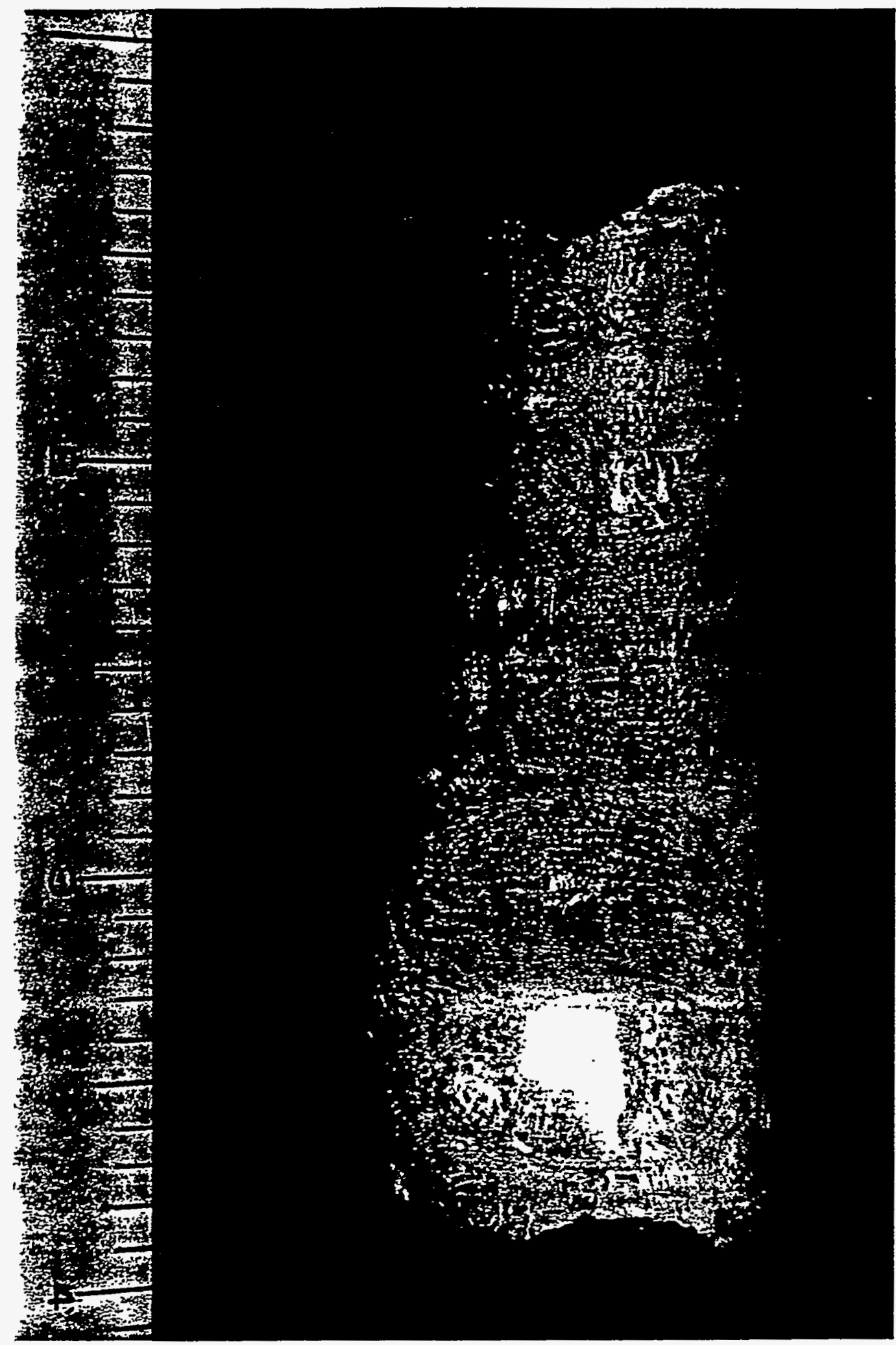

Figure 4. Product from run hip-1. A glassy layer can be seen on the outer surface. X-ray powder diffraction lines of sample taken from the interior of this material is shown in Table 2. 